\title{
O DEBATE CAUSALISMO VERSUS SIMULACIONISMO \\ EM FILOSOFIA DA MEMÓRIA \\ COMO NEGOCIAÇÃO METALINGUÍSTICA
}

\section{César Schirmer dos Santos ${ }^{1}$}

\begin{abstract}
RESUMO
Às vezes, o debate entre causalistas e simulacionistas em filosofia da memória é apresentado de tal modo que parece que apenas o simulacionismo é compatível com a psicologia da memória contemporânea. Contudo, ambas teorias são compatíveis com os fatos descobertos pela ciência. Mas se o debate não é sobre a adequação aos fatos, sobre o que é? Nós propomos que este debate é um caso de negociação metalinguística. Causalistas e simulacionistas aceitam o mesmo conjunto de fatos, mas disputam sobre como devemos definir memória e lembrar.
\end{abstract}

Palavras-chave: Causalismo. Memória Episódica. Negociação Metalinguística. Lembrar. Simulacionismo.

\begin{abstract}
Sometimes, the debate between causalists and simulationists in the philosophy of memory is presented in such a way that it seems that only simulationism is compatible with current days' psychology of memory. However, both theories are compatible with the facts discovered by science. But if the debate is not about the adequacy to the facts, it is about what? We propose that this debate is a case of metalinguistic negotiation. Causalists and simulationists accept the same set of facts, but dispute how we must define memory and remembering.
\end{abstract}

Keywords: Causalism. Episodic Memory. Metalinguistic Negotiation. Remembering. Simulationism.

\section{Introdução}

Neste trabalho, apresentamos a disputa em filosofia da memória entre causalistas e simulacionistas (confiabilistas) como um caso de negociação metalinguística. Procederemos da seguinte maneira. Na seção 1, apresentaremos um experimento mental sobre máquinas escaneadoras de lembranças. Com esse experimento, esperamos mostrar que questões sobre a

${ }^{1}$ Professor associado de Filosofia pela UFSM, pesquisador convidado atuando no CONCEPT, Universidade de Colônia, Alemanha. E-mail: cesar.santos@ufsm.br. 
identificação de lembranças requerem a consideração de propostas filosóficas. Na seção 2 apresentamos algumas definições e pressupostos que são importantes para a compreensão deste trabalho. Na seção 3 apresentaremos as principais teorias filosóficas da memória, o causalismo e o simulacionismo (confiabilismo). Na seção 4 voltamos ao experimento mental das máquinas escaneadoras de memórias, agora aplicando ao mesmo as definições, os pressupostos, e as teorias das seções anteriores. Na seção 5 apresentamos a metodologia da negociação metalinguística. Na seção 6, por fim, aplicamos a metodologia da negociação metalinguística ao debate entre causalistas e simulacionistas.

\section{Máquinas Mnem-O-Matic}

Suponha que um cientista use uma máquina muito sofisticada e infalível, a Imagin-O-Matic, para detectar se o participante de um experimento psicológico imagina (sensorialmente em vez de proposicionalmente) um passado contrafatual. ${ }^{2}$ A máquina escanearia o encéfalo do participante da pesquisa e distinguiria lembranças de imaginações de passados contrafatuais. Apesar de tal máquina não existir, ela é possível, pois há uma diferença entre o modo como o encéfalo processa estados mentais sobre o passado atual e sobre o passado contrafatual (DE BRIGARD et al., 2013, 2412). Filósofos naturalistas aceitariam os dados empíricos gerados pela máquina.

Agora suponha que um cientista queira construir uma máquina Mnem-O-Matic para distinguir lembranças de imaginações (novamente, veiculadas por informações sensoriais em vez de proposicionais) do passado atual. O problema é que o plano para a construção do aparelho deve respeitar alguma concepção do lembrar. No entanto, não há dados empíricos que permitam distinguir lembrança de mera imaginação do passado, e há mais de uma teoria (científica e filosófica, mas focaremos só nas filosóficas) do lembrar. Dada essa situação, já do ponto de vista conceitual, sem nem mesmo entrar na questão técnica, mais de um plano para uma máquina MnemO-Matic é possível.

\footnotetext{
${ }^{2}$ Imaginação sensorial: ter uma experiência envolvendo imagens mentais em vez de imagens perceptuais. Imaginação proposicional: supor que um estado de coisas é o caso.
} 
Foquemos em duas variedades de projetos de máquinas Mnem-OMatic, cada uma inspirada em uma das duas principais teorias contemporâneas sobre a natureza do lembrar. Segundo o projeto de uma máquina Mnem-O-Matic causalista C-Mnem-O-Matic, seria preciso rastrear cadeias causais entre experiências e representações para distinguir aquelas apropriadas daquelas desviantes (MARTIN \& DEUTSCHER, 1966). O plano para uma máquina Mnem-O-Matic simulacionista (confiabilista) S-Mnem-OMatic seria diferente. Provavelmente, o aparelho rastrearia duas coisas. Primeiro, a variedade de simulação que o sistema tenta produzir (MICHAELIAN, 2016a, p. 106). Segundo, a confiabilidade do sistema (MICHAELIAN, 2020).

De modo que uma máquina Mnem-O-Matic se distinguiria de uma máquina Imagin-O-Matic não só no tipo de representação que é distinguida, mas também nos requisitos teóricos mínimos para sua construção. Por um lado, uma máquina Imagin-O-Matic opera rastreando propriedades que são conhecidas empiricamente - por exemplo, as diferentes maneiras do sistema de simulação episódica operar em casos de imaginação atual e contrafatual. Por outro lado, se levamos em conta apenas o conhecimento disponível, uma máquina Mnem-O-Matic operaria pelo rastreio de propriedades "filosóficas" do lembrar. Para surpresa de ninguém, tais propriedades são tema de disputa filosófica. Assim, mesmo um filósofo comprometido em propor apenas teorias filosóficas que sejam consistentes com os fatos empíricos poderia rejeitar a leitura da realidade através de uma máquina Mnem-O-Matic. Esta rejeição é possível porque o cientista que construísse uma máquina Mnem-O-Matic estaria deliberadamente seguindo uma visão filosófica (HOCHSTEIN, 2019), e propriedades "filosóficas", diferentemente de propriedades “científicas", são disputáveis por filósofos empiricamente informados.

\section{Algumas definições e pressupostos}

Por mais longos que sejam, estes esclarecimentos se justificam pelo fato de que a filosofia da memória não está suficientemente enraizada na comunidade filosófica de língua portuguesa. Por essa razão, é problemático apresentar uma tese para avaliação sem apresentar, ao mesmo tempo, os re- 
quisitos conceituais para a avaliação. Esses esclarecimentos são a apresentação desses requisitos.

\subsection{Algumas definições}

\subsubsection{Estado, evento e episódio}

Entendemos por estado a instanciação de uma propriedade por um indivíduo, por evento a instanciação de uma propriedade por um indivíduo em um momento, e por episódio uma sequência temporalmente contínua de eventos. Por exemplo, a água estar líquida é um estado, a água estar líquida um minuto atrás é um evento, e a água passar de líquida para gasosa é um episódio.

\subsubsection{Memória episódica e lembrança}

Por lembrança, ou memória episódica, entendemos o evento mental no qual um episódio do passado pessoal é veiculado sensorialmente (em vez de proposicionalmente) para a consciência. ${ }^{3}$ Neste trabalho, a não ser que explicitamente notado de maneira diferente, usamos o termo "lembrança" para denotar apenas memórias episódicas, no sentido de certos eventos mentais que têm a característica de nos apresentar episódios do passado pessoal. Este esclarecimento é importante porque, além de haver lembranças, isto é, certos tipos de eventos mentais que também podem ser chamados de "memórias episódicas", há também o sistema cognitivo responsável por produzir lembranças, ou memórias episódicas, e este sistema é chamado de "sistema da memória episódica", ou por designações semelhantes, mas este sistema não é um evento mental, mas sim um mecanismo neural. Assim, há uma ambiguidade no uso do termo "memória episódica", o qual pode significar seja um tipo de evento mental, seja o sistema responsável por gerar tal tipo de evento mental.

\footnotetext{
${ }^{3}$ Ou seja, sensações e proposições são (propostas de) tipos de veículos de estados mentais. $\mathrm{Na}$ literatura filosófica, é comum a pressuposição (não argumentada e não justificada) que estados mentais podem ser veículados por proposições. É preciso notar, no entanto, que não há evidência empírica de que haja estados mentais veiculados por proposições (CARRUTHERS, 2015).
} 


\subsubsection{Maneiras de distinguir sistemas de memória}

Lembranças são apenas uma das muitas maneiras nas quais a memória se manifesta. Por isso, são várias as maneiras empregadas pelos cientistas e pelos filósofos para classificar os tipos de memórias. Os principais critérios são:

- A quantidade de tempo: Por quanto tempo a informação é armazenada.

- O grau de consciência: O quanto o sujeito está ciente da informação armazenada.

- A atualidade ou disposicionalidade: Se a memória está ativada, ou não.

- O tipo de gatilho: O tipo de coisa que dispara a recuperação da informação.

- O tipo de informação: O tipo de informação armazenada.

Quanto ao tempo de armazenamento, se distingue entre memória de trabalho, memória de curta duração e memória de longa duração. No que diz respeito ao quanto o sujeito está ciente da informação armazenada, se distingue entre memórias procedurais, as quais não são dadas à consciência, e memórias declarativas, as quais são dadas à consciência. Quanto à atualidade, uma memória pode estar operando, ou pode ser uma mera disposição. Por exemplo, o sujeito pode estar acessando a informação, aprendida no passado, que $2+2=4$. Neste caso, a memória (semântica) do sujeito está em operação. Mas pode ser que o sujeito tenha aprendido, no passado, que $2+2=4$, não tenha esquecido essa informação (memória semântica), mas não esteja acessando-a correntemente. Neste caso, a memória é meramente disposicional (RYLE, 2002).

Quando se classifica os tipos de memória a partir da consideração dos tipos de coisas que levam ao disparo da recuperação da informação armazenada, se distingue entre evocação livre (free recall), evocação sugerida (cued recall), e reconhecimento. Uma lembrança (uma memória episódica) costuma ser disparada por algum gatilho ambiental ou introspectivo. 
Quando se classifica os tipos de memórias pelo tipo de informação armazenada, se distingue entre memória declarativa, a qual é dada à consciência e memória procedural, a qual não é dada à consciência. Uma lembrança (uma memória episódica) é um tipo de memória declarativa.

\subsubsection{O sistema de memória episódica}

A capacidade de lembrar se apoia em diversas outras capacidades (SUDDENDORF \& CORBALLIS, 1997). Notadamente, ela requer a capacidade de conceber (1) o tempo e (2) um eu que continua no tempo. Isto é, por se dar como se fosse no passado, lembrança requer a capacidade de conceber o tempo (SZPUNAR, 2011). Além disso, por se dar no passado pessoal, lembrança requer a capacidade de conceber a si mesmo (SUDDENDORF \& CORBALLIS, 1997; TULVING \& SZPUNAR, 2012).

A memória episódica (isto é, o sistema cognitivo responsável por produzir lembranças) representa eventos específicos do nosso passado pessoal. Ela é acompanhada pela experiência de lembrar (isto é, de uma viagem mental ao tempo passado) que se apresenta como um reexperimentar os eventos antes vivenciados. Nas lembranças, o sujeito tende a se colocar no centro dos eventos lembrados. Isto é, lembranças tendem a ser egocentricamente enviesadas - até porque, ao lado dos eventos passados, as paixões passadas da alma também são elementos das lembranças: a carga emocional dos eventos reexperimentados é parte das lembranças. Ou seja, o conteúdo da memória episódica não se limita aos eventos objetivos eles mesmos, dado que as emoções e outras associações são também incluídas no conteúdo mnêmico (KAHNEMAN, 2012).

Se classificamos tipos de conteúdos mentais pela orientação temporal, então os contrastes mais relevantes da lembrança são a percepção, evento mental no qual se representa um episódio presente, e a prospecção, evento mental no qual se representa um episódio futuro (ARISTÓTELES, 2012; SHANTON \& GOLDMAN, 2010).

Se focamos em sistemas ou mecanismos cujos outputs são dados à consciência, e em virtude dos quais tais tipos de eventos mnêmicos são realizáveis em humanos (ROBINS \& CRAVER, 2009), então os contrastes 
mais relevantes em relação à memória episódica são a memória semântica, isto é, o dispor de informações de caráter proposicional, e a memória autobiográfica, a qual é uma construção de caráter narrativo. A memória semântica é um registro objetivo de fatos, significados, conceitos e conhecimentos sobre o mundo exterior que aprendemos ao longo de nossas vidas. Trata-se de um registro impessoal, independente da experiência pessoal, que como tal é partilhável com os outros. Memória episódica e memória semântica se diferenciam porque a memória episódica envolve a recuperação de informação aprendida num episódio específico e também de algo sobre a própria experiência de aprendizado, enquanto a memória semântica envolve apenas a recuperação de informação aprendida num episódio específico, sem referência ao episódio de aprendizado ele mesmo.

No jargão dos filósofos, a memória episódica é chamada de memória experiencial, e a memória semântica é chamada de memória proposicional (LOCKE, 1971). A memória experiencial é evocação de partes da experiência original de modo tal que essa evocação permite ao sujeito reviver ou reexperimentar como é estar na situação original que levou à aquisição da memória. Ao alegar ter uma memória experiencial, um sujeito também alega que ele mesmo experienciou o evento que levou à aquisição da memória. Ao ter uma memória experiencial, o sujeito representa o evento vivenciado do ponto de vista da primeira pessoa. A representação envolve experiências de qualidades e imagens.

A memória episódica se distingue da memória autobiográfica porque informação contida na memória episódica não é de natureza narrativa, mas antes de tudo sensorial. A representação da realidade passada e da experiência passada no lembrar episódica é icônica em vez de proposicional. "Tal como a imaginação e a fantasia, a memória experiencial é um estado icônico - grosso modo, um estado que pode ser concebido como um tipo de apresentação teatral para si mesmo" (BERNECKER, 2015, p. 438, nossa tradução). ${ }^{4}$ Casos de memória proposicional tem a forma "S lembra que p", no sentido de "S acredita que p", ou "S sabe que p" (TULVING, 1989; KLEIN 2014). "p" está por uma proposição verdadeira. A memória proposicional se

4 "Like imagination and fantasy, experiential memory is an iconic state - roughly one that can be conceived as a sort of theatrical presentation to oneself." (BERNECKER, 2015, p. 438). 
diferencia da memória episódica por não se limitar àquilo que o sujeito ele mesmo experimentou em primeira mão. Por isso, a memória proposicional não requer experiências qualitativas e imagens.

Apesar de haver similaridades entre, por um lado, memória episódica e memória experiencia e, por outro lado, memória semântica e memória proposicional, há diferenças entre as duas distinções. Por um lado, a memória episódica se distingue da memória semântica pelo requisito da consciência autonoética. Por outro lado, a memória experiencial se distingue da memória proposicional porque a memória experiencial se limita àquilo que o sujeito ele mesmo experienciou. ${ }^{5}$

A denominação "memória episódica" é relativamente recente (TULVING, 1972). No entanto, é razoável supor que a memória episódica é o assunto central de obras filosóficas clássicas, como por exemplo o tratado $D e$ Memoria et Reminiscentia, de Aristóteles (2012), além dos capítulos sobre memória dos Princípios da Psicologia (JAMES, 1890) e da Análise da Mente (RUSSELL, 2005b).

Uma lembrança é uma representação por (1) ser sobre algo (um episódio passado), (2) ter conteúdo definido por condições de sucesso (ou condições de acurácia), e (3) apresentar algo (um episódio passado) de certa maneira (modo de apresentação). De modo que podemos dizer que a estrutura de uma lembrança tem três elementos: "(1) o ato de lembrar, (2) o episódio lembrado, e (3) o modo de apresentação deste episódio" (ROWLANDS, 2018, p. 283). O segundo elemento se relaciona ao conteúdo, isto é, àquilo que é representado de certa maneira (modo de apresentação).

\footnotetext{
${ }^{5}$ Talvez seja interessante usar a distinção entre memória visual e memória verbal para se realçar a distinção entre memória episódica e memória semântica. A memória visual é a lembrança da aparência de um objeto, e a memória verbal é a lembrança da descrição de um objeto. Trata-se de uma distinção análoga à distinção entre conhecimento por familiaridade e conhecimento por descrição (RUSSELL, 2005a). A memória semântica, tal como a memória visual, envolve informação de natureza sensorial, e a memória semântica, tal como a memória verbal, envolve informação de natureza linguística. Até este ponto, ao menos, a distinção entre memória visual e memória verbal é de alguma valia para se distinguir entre memória episódica e memória semântica. Porém, não se pode reduzir a memória episódica à memória visual, pois lembranças podem envolver informação sensorial não-visual. Também não se pode reduzir a memória semântica à memória verbal, pois há memórias semânticas que não são descrições de objetos, mas sim conhecimento de fatos. Além disso, é possível formar uma imagem a partir de uma descrição. Além disso, a memória episódica envolve imagem mental em vez de imagem visual, e não está claro se as imagens mentais são mais parecidas a visualizações ou a descrições (BERNECKER, 2015, p. 439).
} 


\subsubsection{Autonoese}

Por autonoese, ou consciência autonoética, entendemos a habilidade de imaginar-se, a partir de certa perspectiva, no tempo subjetivo, em uma localização temporal diferente daquela que o agente ocupa no tempo objetivo (TULVING, 2002a). A autonoese distingue as lembranças de outros tipos de memórias (semântica e autobiográfica, por exemplo), mas a prospecção e a imaginação de passados contrafatuais também são estados autonoéticos. De modo que a autonoese pode ser condição necessária para o lembrar, mas não é condição suficiente, pois há vários tipos de estados mentais que envolvem consciência autonoética. A evidência em favor da existência de estados de consciência autonoética vem do estudo de pacientes amnésicos tais como o paciente $\mathrm{KC}$, quem tinha inteligência e memória semântica normais, mas era incapaz de lembrar, prospectar ou imaginar-se em um tempo subjetivo (TULVING, 1989). Ou seja, lembramos episodicamente quando temos uma experiência autonoética com viagem no tempo subjetivo para o passado pessoal no mundo atual (SANT'ANNA, 2018). Mas há estados autonoéticos que não são lembranças. $\mathrm{O}$ mecanismo da autonoese também opera na prospecção, por exemplo.

A memória semântica é dada à consciência, mas não requer estados de consciência autonoética. Trata-se, em vez disso, de pensamento conceitual que é aplicável a diversas circunstâncias. Para testar se um estado mnêmico é semântico, pode-se aplicar o seguinte teste: Se "S lembra que p" pode ser interpretado, sem perda significativa, como "S crê que p", ou "S sabe que p", então trata-se de memória semântica em vez de memória episódica (TULVING, 1989; KLEIN, 2014).

\subsubsection{Tempo subjetivo}

Por tempo subjetivo entendemos o passado, tal como este se apresenta na lembrança e na imaginação contrafatual, e o futuro, tal como esse se apresenta na prospecção (TULVING, 2002a). Este tempo é subjetivo por ser imaginado, mas também por ser o tempo típico do "nosso senso de existência continuada no mundo" (SZPUNAR, 2011, p. 409, nossa tradução). Ser capaz de conceber o tempo subjetivo, tal como ser capaz de ver, é algo que 
nos permite realizar várias tarefas cognitivas: lembrar, prospectar, e imaginar passados alternativos (SZPUNAR, 2011, p. 409). Uma pessoa saudável pode navegar no tempo subjetivo através de estados de consciência autonoética (TULVING, 1985, p. 5). É importante notar que a temporalidade subjetiva que se dá através da consciência autonoética sempre envolve a imaginação de si mesmo em algum episódio descolado da realidade física. Isto é, trata-se, ao mesmo tempo, de um tempo ao qual o eu se projeta, e de uma base de projeção para o eu (SZPUNAR, 2011, p. 410).

\subsubsection{Mnemicidade}

Por mnemicidade entendemos a propriedade ou conjunto de propriedades que faz com que uma experiência sobre o passado pessoal que é veiculada imaginativamente (em vez de proposicionalmente) seja uma lembrança em vez de ser mera imaginação (MICHAELIAN \& SUTTON, 2017).

\subsubsection{Hipótese da simulação episódica construtiva}

Por hipótese da simulação episódica construtiva entendemos a teoria empírica segundo a qual lembrança e prospecção partilham os mesmos mecanismos neurais (ADDIS, WONG \& SCHACTER, 2007; SCHACTER, ADDIS \& BUCKNER, 2007). Sólidos dados empíricos evidenciam que há sobreposição entre os mecanismos neurais e psicológicos do lembrar, do prospectar e do imaginar episódios que não se deram de fato no passado pessoal (OKUDA et al., 2003, p. 1371; DE BRIGARD et al., 2013, p. 2412). Por que isso se dá? Segundo a hipótese mais aceita, porque há um mecanismo subpessoal que permite ao agente navegar no tempo subjetivo do mundo atual ou de mundos meramente possíveis (TULVING, 1985; SUDDENDORF \& CORBALLIS, 1997; DEBUS 2014, p. 348).

As similaridades entre o lembrar e o prospectar dizem respeito ao tipo de informação e aos tipos de processos envolvidos. Quanto ao tipo de informação, lembranças e prospecções envolvem a representação de episódios nos quais figura o sujeito em um tempo passado ou futuro (TULVING, 2002b; SZPUNAR, 2011; MICHAELIAN, 2016a). Quanto aos processos, 
nos dois casos se dá processamento relacional, isto é, o exercício da capacidade de vincular em uma única representação informações que vêm de diversas experiências. Por se dar processamento relacional, torna-se possível a recombinação flexível, isto é, o exercício da capacidade de extrair informação de diversos episódios e vinculá-los em um único episódio (SCHACTER et al., 2018, p. 42).

\subsection{Alguns pressupostos}

\subsubsection{Pressupostos metafisicos}

A metafísica é uma investigação sobre como a realidade é, nos seus traços mais gerais (MOORE, 2012). Será que o tempo existe? Será que há universais, ou será que só existem entidades concretas e singulares? Essas são questões metafísicas paradigmáticas. Além dessas questões metafísicas que dizem respeito à realidade vista no grau máximo de generalidade, há também questões metafísicas que dizem respeito - metaforicamente - a regiões, tópicos, ou aspectos da realidade. Nosso problema diz respeito a como as lembranças são. Nós vamos supor que existem lembranças, e que existem estados mentais nos quais imaginamos nossos passados pessoais. A partir dessas suposições, nos propomos a responder a seguinte questão: o que diferencia uma lembrança de uma mera imaginação do passado pessoal? Ou seja, nossa questão diz respeito à identidade, ou diferença, das lembranças em relação às fantasias sobre o passado pessoal.

\subsubsection{Pressupostos epistemológicos}

Além das duas pressuposições ontológicas apresentadas acima - que existem lembranças e que existem fantasias sobre o passado pessoal, também partiremos da seguinte pressuposição epistemológica:

Se S lembra de E, então E aconteceu.

Isto é, não há lembrança do que não aconteceu. Definamos aparente lembrança como imaginação de algo que não aconteceu (ROBINS, 2020). 
Se $\mathrm{S}$ acha que lembra de algo que não aconteceu, então $\mathrm{S}$ tem uma aparente lembrança, mas não tem uma lembrança. O ponto, no entanto, é polêmico, pois há quem defenda que uma aparente lembrança é, bem ou mal, uma lembrança (FERNÁNDEZ, 2019). Acreditamos, no entanto, que tratar aparentes lembranças como lembranças genuínas é contraintuitivo, e acrescenta uma camada desnecessária de dificuldade a uma investigação que já é suficientemente complexa. Por isso, consideraremos que só há lembrança do que aconteceu. Ou seja, de acordo com o vocabulário dos epistemólogos, lembranças são factivas (BERNECKER, 2017a, 2017b).

Uma segunda pressuposição epistemológica é que só é possível lembrar do que foi experienciado no passado:

Se S lembra de E, então S experienciou E.

Ou seja, há episódios e eventos que fazem parte do passado pessoal de S, mas que nunca serão lembrados porque S não os experienciou quando eles estavam ocorrendo.

\section{As principais teorias filosóficas da memória}

Alguns problemas filosóficos são intrinsecamente técnicos. Por isso, estão afastados das considerações típicas do senso comum. Por exemplo, as pessoas em geral não costumam se importar com a questão sobre a natureza do conhecimento, muito embora esse seja um problema filosófico de primeira importância. No entanto, o problema da distinção entre lembrar e imaginar é diferente, pois não é raro que alguém se pergunte se está, ou não, lembrando do que representa. De modo que a questão sobre a relação entre lembrar e imaginar é viva mesmo quem nunca se interessou e nem se interessa por filosofia. Levando em conta esse fato, uma maneira didática de introduzir as principais teorias filosóficas contemporâneas é através do foco no problema da mnemicidade, o qual pode ser resumido na seguinte questão:

Há diferença entre lembrar e imaginar o passado? 
Diferentes teorias da memória nos fornecem diferentes respostas a esta questão - e também diferentes maneiras de se entender a pergunta. Os debates contemporâneos em filosofia da memória contemplam duas maneiras de apreender a questão. Em primeiro lugar, a partir do modo como Aristóteles (2012) soluciona problemas levantados pela "teoria" platônica da representação mental, podemos entender a pergunta da seguinte maneira:

É necessário haver um vínculo causal entre a experiência passada do evento e a representação presente deste mesmo evento?

Nos debates contemporâneos sobre esta questão, há três tipos de teorias:

- Teorias causais da memória.

- Teorias híbridas da memória.

- Teorias pós-causais da memória (MICHAELIAN \& ROBINS, 2018).

A questão acerca da mnemicidade também pode ser entendida de uma segunda maneira:

A relação de identidade ou diferença entre lembrar e imaginar o passado é de natureza ou de grau?

Quando se entende o problema da mnemicidade deste modo, estamos lidando com o debate contemporâneo acerca da continuidade ou descontinuidade entre, por um lado, lembrar, e, por outro lado, imaginar o passado. Há dois grupos de teorias:

- Continuísmo.

- Descontinuísmo. 


\subsection{O causalismo "clássico"}

Segundo o causalismo "clássico" (MICHAELIAN \& ROBINS, 2018), um sujeito $S$ lembra (em vez de imaginar) quando as seguintes condições são satisfeitas:

- Condição de acurácia: $\mathrm{S}$ representa o passado com o mínimo de acurácia,

- Condição de experiência passada: $\mathrm{S}$ experienciou em primeira mão (perceptualmente ou introspectivamente) o passado, e

- Condição de causalidade: Há vínculo causal entre os conteúdos da experiência passada de S e a representação presente de S (MARTIN \& DEUTSCHER, 1966, p. 166).

Digamos que houve bolo de chocolate na festa de aniversário de dez anos do sujeito que representa o passado. Dado este fato, representar um bolo de baunilha seria uma violação da condição de acurácia. Mas digamos que, durante a festa, o sujeito estava tão ocupado brincando com os amigos que nunca prestou a menor atenção ao bolo - de modo que não houve oportunidade para que os mecanismos cognitivos do corpo do sujeito registrassem informação sobre o bolo. Ainda assim, no presente, por acaso, ou por uma causa não relacionada à festa de aniversário de dez anos, o sujeito representa um bolo de chocolate. Neste caso, ele não lembra, pois representar um bolo de chocolate sem tê-lo experienciado em primeira mão é uma violação da condição de experiência passada. Por fim, digamos que o agente prestou atenção ao bolo de chocolate de outro aniversário, e o represente como sendo do seu aniversário. Neste caso, de novo, ele não lembra, pois representar um bolo de chocolate por outra causa que não a experiência passada é uma violação da condição de causalidade.

A teoria da causalidade foi desenhada para ser uma explicação do conceito cotidiano de lembrança (MARTIN \& DEUTSCHER, 1966, p. 166; DEUTSCHER, 1989, p. 59; LE POIDEVIN, 2007, p. 24). Isto a torna bastante plausível. No entanto, isso não impede que a teoria causal se ajuste bem à psicologia da memória, pois a condição de causalidade estabelece que 
é preciso haver conexão causal entre a experiência anterior e a representação posterior, e isso provavelmente se daria via traços de memória, também conhecidos como engramas (BERNECKER, 2008, cap. 3), os quais são entidades com boa reputação na psicologia da memória (KITAMURA et al., 2017). ${ }^{6}$

\subsection{O causalismo "neoclássico"}

A teoria "neoclássica" (MICHAELIAN \& ROBINS, 2018) de Bernecker (2010) pode ser considerada um aprimoramento e aprofundamento da teoria "clássica" proposta por Martin e Deutscher. Metafisicamente, Bernecker explicita que lembrança requer identidade pessoal, pois aquele que lembra tem que ser a mesma pessoa que experienciou o episódio representado. $^{7}$

Epistemologicamente, em primeiro lugar, Bernecker apura condição de acurácia através da distinção entre acurácia com respeito ao episódio passado, ou factividade, e acurácia com respeito à experiência passada do episódio, ou autenticidade. Em segundo lugar, Bernecker deixa claro que as três condições propostas por Martin e Deutscher tornam possível lembrar sem acreditar. Este é o problema da lembrança ignorante (ignorant remembering), cujo exemplo clássico é o caso do pintor (MARTIN \& DEUTSCHER, 1966, p. 167). Digamos que se comissione um pintor para pintar uma tela figurativa, mas totalmente imaginária, e o pintor desenhe uma situação que lhe parece fictícia, mas que é reconhecida pelos seus pais como sendo a de um lugar que ele visitou apenas uma vez durante a infância. Nes-

\footnotetext{
${ }^{6}$ A teoria causal da memória é compatível com a visão dos traços da memória localizados (ROBINS, 2016, 2017), e também com a teoria dos traços da memória distribuídos (SUTTON, 1998). É preciso distinguir a questão sobre se os engramas são localizados ou distribuídos, a qual diz respeito ao substrato material, da questão acerca do conteúdo mnêmico, o qual pode ser transmitido ou reconstruído. A teoria causal da memória é compatível com a visão transmissionista, segundo a qual o conteúdo da experiência anterior é transmitido via engramas, mas também é compatível com a teoria reconstrucionista, segundo a qual o engrama permite a reconstrução, no presente, de conteúdo relacionado àquele da experiência anterior que causou a modificação neural que é o engrama. Ou seja, a teoria causal da memória não requer que lembrar seja reproduzir passivamente o que foi codificado - mesmo sendo o caso que aquilo que foi lembrado no presente foi causado por aquilo que foi experienciado no passado (MICHAELIAN \& ROBINS, 2018, 21).

${ }^{7}$ A tese que lembrança pressupõe identidade pessoal tem consequências para as teorias que explicam a identidade pessoal via lembranças. Ou seja, se Bernecker está certo, então há problemas para as teorias psicológicas da identidade pessoal. Infelizmente, não temos como desenvolver este tema neste trabalho.
} 
te caso, a representação é acurada, houve experiência no passado, e a melhor explicação é que o pintor lembra, apesar de achar que não lembra (BERNECKER, 2010, p. 276). Ou seja, a representação satisfaz todas as condições requeridas por um filósofo causalista da memória para ser uma lembrança (em vez de mera imaginação), mas não envolve crença seja de vivência passada, seja de estar lembrando no presente. Por essa razão, para Bernecker, assim como para Martin e Deutscher, este é um caso de lembrança. Como veremos, o ponto é polêmico, e é questionado por defensores de teorias híbridas do lembrar. ${ }^{8}$

\subsection{Teorias híbridas da memória}

Os causalismos "clássico" e "neoclássico" tratam as condições apresentadas por Martin e Deutscher como suficientes para distinguir entre lembrar e imaginar. Uma teoria híbrida da memória trata as condições apresentadas por Martin e Deutscher como necessárias mas não suficientes para distinguir entre lembrar e imaginar (MICHAELIAN \& ROBINS, 2018, p. 19).

Há dois tipos de teorias híbridas da memória. Em primeiro lugar, as teorias causais-epistêmicas da memória focam no problema da relevância epistêmica. Voltando ao caso do pintor, de acordo com a teoria da relevância epistêmica, uma variedade de teoria causal-epistêmica da memória, se a experiência supostamente mnêmica não tem relevância epistêmica para ele, isto é, não o leva a formar crenças relevantes sobre o passado pessoal, então não se trata de lembrança, mas sim de imaginação (DEBUS, 2010). Isto é, voltando ao problema da lembrança ignorante, se o sujeito tem uma experiência sobre o passado pessoal que lhe parece ser imaginativa, mas o conteúdo dessa experiência foi vivenciado no passado, e a representação posterior foi causada pela representação anterior, então estamos em uma situação que o causalista "clássico" reconheceria como uma ocorrência de lembrança, em vez de imaginação, pois a informação é acurada e foi causada apropriada-

\footnotetext{
8 Além dos causalismos "clássico" e "neoclássico", uma terceira variedade de teoria causal da memória é o causalismo procedural, segundo o qual os vínculos causais relevantes não dizem respeito aos conteúdos mentais, mas sim aos processos neurais (PERRIN, 2016, 2018). Infelizmente, não temos como aprofundar a apresentação do causalismo procedural neste trabalho.
} 
mente (BERNECKER, 2010, p. 276). No entanto, o filósofo causal-epistemista discorda, pois o sujeito não tem disposição de formar crenças sobre sua vida passada a partir do que representa no presente. De modo que falta ao causalismo "clássico" um elemento necessário para distinguir entre lembrar e imaginar: a relevância epistêmica da experiência supostamente mnêmica, mas imaginativa. Assim, para o filósofo causal-epistemista, lembrança requer representação que seja:

1 Condição de acurácia: Minimamente acurada.

2 Condição de experiência: Sobre algo que foi vivenciado no passado pessoal.

3 Condição de causação: Causada pela experiência anterior relevante.

4 Condição de relevância epistêmica: Epistemicamente relevante para o sujeito (DEBUS, 2010).

De modo que há mera imaginação quando a representação do passado pessoal (1') não é minimamente acurada, (2') não é sobre algo que foi vivenciado no passado, (3') não é causada pela experiência anterior relevante ou (4') não tem relevância epistêmica para o sujeito.

Em segundo lugar, as teorias causais-autonoéticas da memória requerem, além das três condições clássicas, que a consciência autonoética seja uma condição necessária a mais para distinguir entre memória e imaginação (KLEIN, 2014). Essas teorias são diretamente inspiradas pelo modo como o psicólogo canadense Endel Tulving passa a definir memória episódica após a investigação do caso do paciente amnésico $\mathrm{KC}$, quem conhecia fatos que se deram no seu passado pessoal (ou seja, KC tinha memória semântica), mas não era capaz de lembrá-los (TULVING, 1985). Assim, KC tinha informação sobre episódios específicos do seu passado pessoal, episódios esses que se deram em contextos espaciotemporais delimitados. $\mathrm{Ou}$ seja, KC sabia o que, onde, e quando algo aconteceu na sua vida pregressa. Isto é, KC tinha conhecimento www (what, where, when) de episódios da sua vida passada, o qual passaria no teste da teoria causal "clássica", pois se tratava de representações (talvez proposicionais) acuradas que, segundo a explicação mais simples, foram causadas pelos episódios representados. 
Mas, por faltar a $\mathrm{KC}$ o tipo de estado de consciência que é típico do lembrar, não parece adequado se dizer que ele lembrava de tais episódios. De modo que a autonoese se mostra uma condição necessária para o lembrar. Como a autonoese também é necessária para a imaginação de si mesmo no passado e para a prospecção, a falta do elemento autonoético não transforma a representação supostamente imaginativa em mnêmica, mas sim em semântica, ou conceitual. Ou seja, consciência autonoética é condição necessária, mas não suficiente, para o lembrar.

Por fim, podemos observar que, ainda que a teoria causal-epistêmica e a teoria causal-autonoética sejam duas variedades distintas de teorias híbridas do lembrar, é possível partir de uma para chegar à outra. Por um lado, a autonoese é a melhor explicação para o fato que o sujeito tem a tendência a crer no que experiência como lembrança (MICHAELIAN \& ROBINS, 2018, p. 20). Por outro lado, a atitude epistêmica de crer parece ser o efeito mais distintivo do fato de se experienciar o passado atual (ainda que em um tempo subjetivo) autonoeticamente (MAHR \& CSIBRA, 2018, p. 1).

\subsection{Causalismo: em resumo}

Com respeito ao problema da mnemicidade, isto é, à questão do que diferencia lembrar de imaginar, os causalistas em geral defendem que há lembrança quando uma experiência anterior de um episódio é causa de uma representação minimamente acurada desse episódio. Sob esta condição, há lembrança em vez de imaginação. Assim, há imaginação quando a representação presente do que foi experienciado no passado é muito inacurada ou não há vínculo causal entre experiência passada e recordação presente.

\subsection{Teorias pós-causais da memória}

Teorias pós-causais da lembrança são tais que não requerem vínculo causal entre um episódio experienciado no passado e a representação posterior desse episódio (MICHAELIAN, 2016a). O simulacionismo é a principal teoria pós-causal da memória. 


\subsection{Simulacionismo, ou teoria da confiabilidade}

O simulacionismo é constituído por duas teses. Primeiro, que lembranças são geradas por um mecanismo cognitivo cuja função é produzir simulações de episódios passados ou futuros (MICHAELIAN, 2016a). Segundo, que há lembrança em vez de mera imaginação do passado quando o mecanismo realiza confiavelmente a tarefa de simular o que se deu no passado pessoal no mundo atual (SANT'ANNA \& MICHAELIAN, 2019). De modo que, no que diz respeito à questão da mnemicidade, o simulacionismo é uma teoria da confiabilidade. Para explicar como o sistema de imaginação episódica (o qual é responsável por lembranças e pela imaginação do futuro) é capaz de nos fornecer conhecimento do passado pessoal, o simulacionista propõe que este sistema opera confiavelmente quando opera com o fim de simular o que se deu, de fato, no passado (MICHAELIAN, 2016a).

Os simulacionistas seguem de perto a hipótese da simulação episódica construtiva, segundo a qual humanos dispõem de uma capacidade geral de imaginar episódios passados ou futuros, sendo as lembranças apenas uma das manifestações dessa capacidade (ADDIS, WONG, \& SCHACTER, 2007; ADDIS, 2018). Quando ao funcionamento desta capacidade, o mesmo mecanismo opera, da mesma maneira, em todos os casos: informações de vivências passadas são empregadas para se construir representações dos eventos alvos, quer estes sejam passados, quer sejam futuros (DE BRIGARD, 2014; MICHAELIAN, 2016b). Dados esses fatos, é fácil explicar os casos de lembranças inacuradas, pois esses acontecem porque o mecanismo que gera lembranças tem como meta fundamental a recombinação flexível de informações em vez da reprodução fiel do passado (DE BRIGARD, 2014, p. 158). Assim, o simulacionismo parte do fato que todos os tipos de imaginação episódica, incluindo a lembrança, são realizados pelas mesmas estruturas encefálicas. A partir desse fundamento, o simulacionismo rejeita a necessidade de conexão causal entre experiência e lembrança da experiência, pois se o mecanismo não opera assim no caso da imaginação do futuro, por que operaria assim na lembrança? 


\subsection{O debate entre continuístas e descontinuístas}

A teoria simulacionista da lembrança motiva um debate sobre a relação entre o lembrar e o imaginar episódico. Há duas visões centrais, o continuísmo e o descontinuísmo. Por um lado, as evidências empíricas que servem de motivação direta para o simulacionismo são tais que parecem sustentar a tese continuísta: lembrar é apenas uma entre outras variedades de viagem no tempo subjetivo (SANT'ANNA, 2018, p. 59). Por outro lado, uma visão mais de perto das evidências empíricas parece sustentar a tese descontinuísta, a qual é a negação da tese continuísta (PERRIN, 2016). Além disso, ainda em favor do descontinuísmo, parece haver importantes diferenças metafísicas entre lembrar e imaginar (DEBUS, 2014).

Este é um debate em andamento. Nos limitaremos a apresentar razões em favor de cada uma das posições. Por um lado, em favor do continuísmo, há o fato que lembrança e imaginação do futuro partilham o mesmo mecanismo neural (SCHACTER, ADDIS \& BUCKNER, 2007; ADDIS, 2018). Por partir desse fato, o continuísmo se mostra propenso a ser uma teoria naturalista, no sentido de ser uma proposta consistente com os achados das pesquisas empíricas (SPINELLA, 2019).

Por outro lado, em favor do descontinuísmo, é preciso observar, em primeiro lugar, que as pesquisas empíricas encontram diferenças entre os mecanismos do lembrar e do imaginar (ADDIS, WONG \& SCHACTER, 2007; ADDIS et al., 2009; DE BRIGARD et al., 2013; PERRIN, 2016). Em segundo lugar, os descontinuístas observam que o lembrar envolve diferenças normativas em relação ao imaginar. Lembrar o passado pessoal é ter sucesso em uma tarefa epistêmica que pode dar errado seja porque a representação é inacurada, seja porque não tem a devida relação com a experiência passada (DEBUS, 2014). Já o imaginar o futuro é diferente, pois é útil mesmo quando representa algo que não acontecerá exatamente por ter sido imaginado com antecedência.

\section{Debates científicos e filosóficos}

O experimento mental das máquinas Mnem-O-Matic serve para que distingamos entre discussões científicas e discussões filosóficas acerca do 
critério de mnemicidade. Suponha que o sistema de simulação episódica de um participante de uma pesquisa funcione de maneira não-confiável - mais especificamente, que o mecanismo de representação autonoética do participante às vezes (mas com frequência suficiente para caracterizar inconfiabilidade) misture o passado atual com o passado meramente possível. Suponha também que haja uma cadeia causal não-desviante a experiência prévia do episódio E e a representação presente do episódio E. Neste caso, uma máquina C-Mnem-O-Matic indicaria que o participante da pesquisa lembra (em vez de imaginar) seu passado atual. O filósofo da causalidade diria,

"Sim, isto é um caso de lembrança, pois há um vínculo causal entre a experiência passada e a representação presente."

Mas o filósofo da confiabilidade diria,

"Não, este não é um caso de lembrança, pois o sistema de simulação episódica do participante da pesquisa não opera confiavelmente."

Agora suponha que outro participante em pesquisa seja testado em uma máquina S-Mnem-O-Matic, sendo o caso que o sistema de simulação episódica do participante da pesquisa seja confiável. Suponha também que há uma cadeia causal desviante entre a experiência de E e a representação de E. Neste caso, o filósofo da confiabilidade diria,

"Sim, este é um caso de lembrança, pois o sistema de simulação episódica do participante da pesquisa opera confiavelmente."

Mas o filósofo causal diria,

"Não, este não é um caso de lembrança, pois não há vínculo causal apropriado entre a experiência anterior de E e a representação posterior de E." 
Seria este um desacordo sobre os fatos empíricos? Não. Caso uma máquina C-Mnem-O-Matic fosse construída, haveria fatos que estabeleceriam se, ou não, um certo mecanismo estaria rastreando uma cadeia causal. Tais cadeias causais são fisicamente possíveis, assim como uma máquina CMnem-O-Matic. Assim, um filósofo naturalista deveria aceitar tais fatos, pois ser naturalista em filosofia é propor hipóteses e teorias que sejam fisicamente, biologicamente, e psicologicamente possíveis (SPINELLA, 2019). Algo similar se daria caso uma máquina S-Mnem-O-Matic fosse construída, pois é fisicamente possível que o sistema de simulação episódica tente representar o passado pessoal atual, e também que esse sistema opere de maneira confiável. Assim, se houver desacordo entre os filósofos, esses não dizem - ou, ao menos, não precisam dizer - respeito aos fatos. Ambos podem aceitar os fatos, e devem fazer isso, caso sejam naturalistas. No entanto, os fatos subdeterminam a teoria. Sendo esse o caso, a escolha da teoria tem que ser movida pelos fatos e por algum outro elemento adicional, o qual é diferente dos fatos.

É esse outro elemento adicional o que explica a aceitação ou rejeição da leitura da realidade por uma máquina Mnem-O-Matic. Esse é um elemento filosófico, pois independente dos fatos, os quais são o assunto primordial das ciências naturais.

\section{Negociação metalinguística}

Nesta seção, apresentamos a metodologia filosófica da negociação metalinguística de maneira em parte independente dos tópicos deste artigo, os quais dizem respeito à filosofia da memória. Posteriormente, aplicaremos esta metodologia ao nosso tema.

\section{1. Ética conceitual}

Um debate sobre como um termo deve ser usado diz respeito à ética conceitual, área de investigação cuja questão-chave é:

Que conceitos devemos empregar em certos contextos? 
A ética conceitual se vincula a uma engenharia conceitual, isto é, à tarefa de comparar candidatos a conceitos com a finalidade de avaliá-los através de critérios independentes, para, se for preciso, revisar, substituir ou eliminar os conceitos em foco (BELLERI, 2020, p. 2). Diversas disputas filosóficas ou são exercícios de ética conceitual, ou podem ser reinterpretadas como tais de maneira iluminadora. Há diversas maneiras de se realizar tal exercício, mas neste trabalho nos interessa apenas as negociações metalinguísticas (PLUNKETT E SUNDELL, 2013). Considerações sobre a ética conceitual levam em conta dois aspectos normativos das crenças. Em primeiro lugar, é importante que as crenças sejam verdadeiras, em vez de falsas. Mas a verdade das crenças não é suficiente. Além da verdade, é preciso que as crenças sejam constituídas pelos conceitos mais apropriados (KITSIK, 2020, pp. 1046-47). Pode-se discutir, e se discute, que conceitos seriam esses. Há, no entanto, suficiente consenso quanto às características de tais conceitos. Há duas possibilidades: ou esses conceitos são tais que refletem a própria estrutura da realidade, trinchando a natureza nas suas juntas, ou esses conceitos são tais que constituem um esquema conceitual maximamente valioso para a sobrevivência e a investigação teórica (THOMASSON, 2017b, p. 10). Uma investigação sobre a ética do uso de um certo conceito em certo debate ontológico ou metafísico pode ser motivada seja pela busca do conhecimento da realidade fundamental, seja pelo interesse na construção de um esquema conceitual que se mostre útil ou valioso para certo fim. Por um lado, alguns filósofos têm como meta trinchar a natureza nas suas juntas. Para esses filósofos, devemos empregar os conceitos que estejam mais próximos de descrever a realidade fundamental (SIDER, 2011). Por outro lado, outros filósofos defendem um pluralismo ontológico tal que diferentes conceitos são propostos porque são úteis para diferentes fins (CARNAP, 1988). Em qualquer um desses casos, uma negociação metalinguística pode ser entendida como uma variação do tema filosófico mais amplo e mais profundo da reflexão sobre a natureza e a correção dos nossos conceitos (BELLERI, 2020, p. 3).

Nas disputas filosóficas, sempre há o risco de um filósofo não estar, de fato, ouvindo e conversando com o outro. Tome o problema que nos interessa neste trabalho, a saber, se há, ou não, diferença entre lembrar e imagi- 
nar o passado, e, caso haja diferença, o que faz com que haja tal diferença o problema da mnemicidade. O seguinte esquema de debate pode vir a ser satisfeito:

Filósofo A: As representações do passado que têm a propriedade $\mathrm{F}$ são lembranças em vez de serem meras imaginações.

Filósofo B: Não é razoável exigir que todas as lembranças tenham a propriedade F.

Eis uma instância deste esquema de discussão:

Filósofo causalista: As representações do passado que têm a propriedade de terem sido causadas pelos episódios representados são lembranças (LE POIDEVIN, 2007).

Objetor: É implausível que todas as lembranças tenham sido causadas pelos episódios representados (SANT'ANNA \& MICHAELIAN, 2019, 9).

O que acontece, neste caso? Acreditamos que há duas interpretações. Na primeira interpretação, considera-se que o debate diz respeito aos fatos. Neste caso, dado que há duas descrições conflitantes, ao menos uma das descrições é incorreta. Isto pode acontecer. No entanto, o problema dessa interpretação é que, no caso de uma discussão filosófica sobre algo que é vagamente conhecido pelas ciências empíricas, como é o caso da lembrança, a própria descrição do fenômeno é algo em disputa. O que nos leva à segunda interpretação, na qual a disputa não diz respeito aos fatos relacionados à lembrança, mas sim aos padrões para se considerar algo um caso de lembrança. Tudo o mais sendo o mesmo, essa interpretação é preferível, pois se ajusta ao fato de que a própria descrição do fenômeno é algo em disputa, e estabelece os parâmetros para que se chegue a uma descrição de fato debatida, ou negociada (PLUNKETT \& SUNDELL, 2013).

Tipicamente, o assunto de uma negociação metalinguística em um debate ontológico é a existência - isto é, a própria noção de existência. Se este assunto é tratado a partir de uma pegada normativa, se pergunta: O que 
se deve entender por "existência"? Sempre mantendo este tipo de pegada, outros tópicos podem ser tematizados da mesma maneira. Por exemplo: O que se deve entender por “objeto"? Mas não apenas assuntos tão gerais. Assuntos mais específicos também podem ser abordados a partir da mesma metodologia. Por exemplo: O que se deve entender por “cor”? Este debate poderia lidar, entre outras coisas, com o problema levantado pelo novo enigma da indução. Por exemplo, o que faz com que um certo corpo seja da cor verde, em vez da cor verzul? (Estamos falando do grue (verzul) de Nelson Goodman (1979).) Eis uma das muitas definições possíveis de verzul:

Verzul: Um objeto é verzul caso seja observado antes de 1955 e seja verde ou não seja observado antes de 1955 e seja azul.

Assim, a desagradável camisa do Grêmio Football Clube de Porto Alegre não é verzul, pois foi observada antes de 1955 e não é verde, mas a camisa do Palmeiras é verzul, pois foi observada antes de 1955 e é verde. Os logos do Twitter e do Facebook também são verzuis, pois não foram observados antes de 1955 e são azuis. Ou seja, a camisa do Palmeiras e os logos dessas duas tensas redes sociais são da mesma cor, verzul. Ou não? A propriedade de ser verzul opera do modo como deveria operar, para ser uma cor? Eis um tema para um debate sobre o que se deve entender por "cor".

Outros termos também podem ser tema de negociação metalinguística. Pode-se debater, por exemplo, o que se deve entender por "bom", "certo", ou "lei", ou por um conetivo lógico, como "não" (BELLERI, 2020, p. 2). Nestes casos, é mais adequado se dizer que o debate é metafísico, isto é, sobre como a realidade é (MOORE, 2012), do que ontológico, isto é, sobre $o$ que existe (QUINE, 2011).

\subsection{Dois usos de predicados vagos}

Para compreender as negociações metalinguísticas, comecemos pela consideração de como usamos predicados vagos, como, por exemplo, "alto". Há duas maneiras de se usar tais predicados, uma descritiva, a outra metalinguística. $\mathrm{O}$ uso descritivo de um predicado vago se dá quando usamos o pre- 
dicado, em certo contexto de conversa, para adicionar nova informação sobre alguma coisa. Por exemplo, no contexto de uma conversa sobre as alturas das pessoas, considerando um padrão de altura que é aceito pelos falantes, a afirmação que Feynman é alto acrescenta informação sobre como as coisas são no mundo. Nesse caso, a condição de verdade para o predicado é estabelecida pelo contexto de uso, o qual, no exemplo, é sobre as alturas de pessoas.

No segundo tipo de uso de um predicado vago, em vez do contexto fixar o significado, o que se dá é que o significado selecionado serve de guia para se chegar ao contexto apropriado. Digamos que a conversa seja sobre o que é considerado ser uma pessoa alta em certo lugar, todos saibam que Feynman é alto, e se afirme que Feynman é alto. Neste caso, não é apresentada nenhuma nova informação sobre Feynman, nem sobre as condições de verdade de "alto". Tudo o que se fez foi fornecer orientações sobre o padrão de altura de pessoas em certo lugar. Ou seja, o termo "alto" é usado de maneira metalinguística para se comunicar como se usa o termo "alto" em certo contexto (BARKER, 2002).

Para entender um pouco melhor os dois contextos, considere como se daria a discordância, em cada caso. Por um lado, quando o contexto guia o significado, o contexto é sobre a altura de uma pessoa segundo padrão de certo lugar, e se diz que Feynman é alto, a discordância diz respeito a quanto Feynman de fato mede. Por exemplo, poderia se objetar que Feynman mede apenas $1,20 \mathrm{~m}$. Neste caso, o desacordo diz respeito aos fatos. Por outro lado, quando, na conversa, o significado leva ao contexto, o contexto que se busca é aquele do padrão de altura em outro lugar, sabe-se a altura de Feynman, e se diz que Feynman é alto, a discordância não diz respeito a quanto Feynman de fato mede, mas sim às características do contexto em debate. Por exemplo, poderia se objetar que no outro lugar Feynman seria considerado baixo. Neste caso, o desacordo diz respeito aos padrões.

Na conversa entre o filósofo causalista e o objetor, o assunto não são os fatos que satisfazem certo padrão, mas sim o padrão a se estabelecer para se determinar os fatos. Por um lado, o filósofo causalista defende que apenas a classe de representações do passado que tenham sido causadas pelos episódios representados sejam consideradas como sendo lembranças, en- 
quanto o objeto alega que deveríamos incluir outras representações na classe das lembranças.

\subsection{O problema da dependência-de-teoria}

Paradigmaticamente, disputas ontológicas dizem respeito a se algum tipo de coisa existe, ou não. McTaggart (2014), por exemplo, nega que o tempo exista. Isso o coloca em conflito com os filósofos que defendem a existência do tempo - por exemplo, os teóricos-A e os teóricos-B do tempo. Outro exemplo é a disputa clássica sobre a existência de universais. Realistas afirmam a existência de universais. Nominalistas negam.

No entanto, esta não é a única maneira de se apresentar uma disputa ontológica. Nos exemplos dados, trata-se de lidar com a questão de se algum tipo de coisa existe, ou não, no nível dos objetos. Apenas para fins didáticos, suponha que tudo o que existe pertença a um conjunto - o qual pode ser entendido, caso se queira, sem que se espere ou se prescreva reificação, como o conjunto das coisas que são abrangidas pelos quantificadores de alcance máximo da lógica de primeira ordem. Este seria o conjunto dos existentes. Será que o tempo é um dos membros deste conjunto? Será que os universais são membros deste conjunto? Estas são questões pertinentes em investigações ontológicas. Porém, não é claro se, e em que medida, as respostas para estas questões são independentes das teorias que descrevem os objetos cuja existência se investiga. Considere o caso de McTaggart. Ele afirma que o tempo não existe porque a existência do tempo depende da existência da série-A, mas a série-A não pode existir - portanto, o tempo não existe. Este é um caso de tese ontológica dependente de uma teoria muito específica. Algo semelhante se dá no caso do debate sobre a existência de universais. Por um lado, os realistas defendem a existência de universais porque estes seriam os legítimos objetos do conhecimento científicos. Por outro lado, os nominalistas negam a existência de universais porque estes seriam meros sons sem denotação independente de entes concretos e particulares.

Ou seja, não haveria debate genuíno, pois debates genuínos exigem uma língua em comum, mas cada parte estaria falando um idioleto diferente. 
“Tempo" significaria uma coisa no idioleto de McTaggart, outra coisa nos idioletos dos teóricos-A e -B. Situação semelhante se daria com respeito ao termo "universal". As disputas, neste caso, parecem ser meramente verbais, pois diriam respeito a quais são os significados de termos tais como "tempo" e "universal". Em uma leitura pouco caridosa, um lado estaria certo, o outro estaria errado. Em uma leitura bastante caridosa, cada lado estaria certo, pois cada lado falaria uma língua diferente. Assim, McTaggart fala uma verdade em mctaggartês ao dizer que a denotação de "tempo" (termo do mctaggartês) não existe existe, assim como o teórico-A fala uma verdade sobre a denotação de "tempo" (termo do teoriquês-A) ao dizer que essa existe, e o teórico-B fala uma verdade sobre a denotação de "tempo" (termo do teoriquês-B) ao falar que essa existe. Semelhantemente, o nominalista fala uma verdade sobre a denotação de "universal" em nominalistês, e o realista fala uma verdade sobre "universal" em realistês. De modo que todos estão certos, não havendo discordância real (THOMASSON, 2017b, p. 2).

Dado este problema de dependência-de-teoria em disputas ontológicas que se dão sobre objetos, uma saída é a ascensão semântica, isto é, a discussão sobre o significado de um termo usado em uma disputa. Por exemplo, debater o significado de "tempo" em vez de debater a existência do tempo, ou o significado de "universal" em vez da existência dos universais. Mas apenas esse movimento, por si só, não nos leva adiante no problema da dependência-de-teoria. ${ }^{9}$ Pois consideremos o caso de McTaggart. Ele explicaria o conceito de tempo a partir do conceito de série-A, o que nos levaria a uma situação análoga àquela que se dá no debate ontológico no nível dos objetos. Algo similar também se daria no caso do debate sobre a existência dos universais. Por um lado, os realistas definiriam universais como os objetos legítimos da ciência. Por outro lado, os nominalistas definiriam universais como meros sons vazios de significado independente.

A dificuldade da mera ascensão semântica como solução para o problema da dependência-de-teoria é que os participantes do debate permanecem em uma atitude meramente descritiva. No debate sobre o tempo, McTaggart descreve o tempo de tal maneira que a conclusão sobre sua ine-

\footnotetext{
${ }^{9}$ Em vez de nos levar adiante, a ascensão semântica é uma espécie de evasão das questões ontológicas de primeira ordem (MARTIN \& HEIL, 1999).
} 
xistência é natural. Seus oponentes, por sua vez, descrevem o tempo de tal modo que a conclusão da sua existência é justificada. Algo semelhante se dá no caso do debate entre realistas e nominalistas. Dada tal configuração dialética, há o risco de não se dar um debate genuíno, pois cada lado apenas proclama sua posição sem, de fato, dar ouvidos às posições dos adversários. Uma solução para resolver esse problema é dar um teor normativo ao debate. Por exemplo, McTaggart e seus oponentes poderiam disputar o que se deveria concluir, segundo critérios independentes, com respeito à questão acerca da existência do tempo. Algo similar poderia se dar no caso do debate entre realistas e nominalistas, e provavelmente em muitos outros debates ontológicos. Assim, o debate ontológico não precisa dizer respeito, prioritariamente, às coisas que fazem parte do conjunto dos existentes. Em vez disso, o foco inicial pode ser no que deve fazer parte deste conjunto (BELLERI, 2020).

\subsection{Conflitos teóricos}

Há conflitos teóricos que se dão no nível dos objetos de estudo e conflitos teóricos que se dão no nível da linguagem que se emprega para investigar os objetos de estudo. Por exemplo, é possível discordar se uma certa obra é arte ou não (conflito sobre um fato relacionado a um objeto), ou pode se discordar sobre o que se deve entender por arte (conflito relacionado a um conceito). $\mathrm{O}$ conflito entre o causalista e o simulacionista não diz respeito aos fatos. Os mesmíssimos fatos são aceitos por todos os participantes do debate. No entanto, isso não encerra o debate. De modo que o debate deve ser sobre outra coisa - segundo nossa proposta sobre o conceito de lembrança.

Há várias maneiras nas quais os falantes podem discordar com respeito à linguagem. No caso do conflito entre a teoria da causalidade e a teoria da confiabilidade, entendemos que o conflito é uma negociação acerca da maneira adequada de se definir o lembrar a partir de elementos teóricos. Nessa negociação, cada disputante usa o léxico do lembrar de modo a prescrever, para a outra parte e para o público em geral, o modo como esse léxico deve ser utilizado. De modo que se trata de uma negociação 
metalinguística sobre a maneira apropriada de se falar e de se pensar sobre o lembrar (PLUNKETT \& SUNDELL, 2013). O filósofo da causalidade e o filósofo da confiabilidade usam o léxico do lembrar diferentemente, cada qual prescrevendo, a partir do seu uso, uma maneira de se entender a natureza do lembrar e de se empregar, consequentemente, tal léxico (THOMASSON, 2017a).

\subsection{Descrição e prescrição}

Um debate metafísico sobre termos (tais como "lembrança") relacionados a conceitos (tais como o conceito de lembrança) pode ser descritivo ou prescritivo. A metafísica descritiva se ocupa do trabalho de cunho quase antropológico de descrever como uma certa população utiliza certo termo ligado a certo conceito (STRAWSON, 2019). A população pode ser uma amostra representativa dos adultos em geral, caso no qual se foca no conceito do senso comum, ou pode ser a população de especialistas relevantes. Quanto ao método para se vincular palavras a conceitos, considera-se que um conceito é delimitado pelos usos dos termos a eles relacionados. Em um slogan: um conceito é uma palavra em um lugar (HACKING, 2009). Assim, a descrição do significado de um termo é um caminho para o debate sobre um certo conceito. No entanto, no caso do conceito de lembrança, e de outros a este relacionados, a descrição do significado não é suficiente para se delimitar o elemento diferenciador do lembrar em relação ao imaginar o passado.

O senso comum estabelece condições necessárias para que um caso seja de lembrança em vez de imaginação, mas isso subdetermina a teoria requerida para se explicar o diferenciador. Considere, por exemplo, a maneira como uma mãe ensina um filho a identificar seus próprios estados mentais mnêmicos. Isso pode se dar através de uma conversa na qual os dois lembram juntos de um episódio. A mãe pergunta se havia mais alguém em uma festa. A criança responde que Davi estava na festa. A mãe observa, docemente que Davi estava na festa, mas que a criança não viu Davi na festa. A criança concorda - e aprende como identificar seus próprios estados mentais mnêmicos (REESE \& CLEVELAND, 2006, p. 35). Esse processo é sufici- 
ente para que a criança aprenda que a lembrança de um certo episódio requer a experiência desse episódio, mas não é suficiente para se estabelecer nenhuma teoria sobre o que diferencia o lembrar do imaginar. Acreditamos que o mesmo se dá com outros processos que levam ao domínio do conceito de lembrança. Isto é, saber diferenciar o lembrar do imaginar não é suficiente para saber o que diferencia lembrar de imaginar.

O mesmo se dá no caso do conceito científico de lembrança. Com respeito à metodologia, cresce o consenso entre os filósofos da memória de que a psicologia da memória deve servir de base para a filosofia da memória (MICHAELIAN, 2016a, p. xiii; MICHAELIAN, DEBUS \& PERRIN, 2018, p. 6). Esse compromisso com a pesquisa empírica se manifesta através de um naturalismo que se limita a propor apenas teorias que são fisicamente, biologicamente e psicologicamente possíveis (SPINELLA, 2019). No entanto, consenso metodológico não acarreta, por si só, consenso teórico, pois os dados empíricos disponíveis permitem mais de uma teoria empírica, e mais de uma teoria filosófica. Ou seja, a situação é de subdeterminação das teorias pelos fatos conhecidos.

Pois considere o caso da muitíssimo influente hipótese da simulação episódica construtiva. Esta é uma teoria psicológica em vez de filosófica. A versão "clássica" desta teoria é constituída por duas teses. Primeiro, que lembrar e prospectar têm a mesma base neural. Segundo, que a função adaptativa do sistema de memória episódica é imaginar o futuro (SCHACTER, ADDIS \& BUCKNER, 2007, p. 659). No entanto, a versão "refinada" desta teoria é constituída apenas pela primeira tese (ADDIS, 2018, p. 82). Essas duas teorias psicológicas se apoiam nos mesmos dados empíricos, mas são diferentes. Ou seja, na pesquisa psicológica corrente sobre a memória episódica, os dados empíricos subdeterminam as teorias científicas. Dada tal situação, não é surpreendente que tais dados de natureza empírica sejam compatíveis com mais de uma teoria filosófica. Isto é, também nesse caso, o domínio do conceito não é suficiente para que se estabeleça o diferenciador. Esta situação abre espaço para que se apresente uma definição teórica de lembrança. Não se trata de convencionar um sentido para o termo, nem de apenas evidenciar um sentido já corrente, mas sim de elucidar o sentido do termo relacionado ao conceito através da inserção do conceito em uma teo- 
ria mais ampla - de preferência sem ruptura com o senso comum e as ciências.

Um metafísico pode propor melhorias nos casos em que a descrição do conceito é fiel ao uso pela população-alvo, mas o conceito resultante da mera descrição se mostra insatisfatório. Pense, por exemplo, no modo como o conceito de memória do senso comum se relaciona com o conceito de passado. As pessoas em geral pensam que lembranças são sobre o passado, mas elas também pensam que o passado não existe mais. No entanto, não é nem um pouco claro como um estado mental poderia ser sobre algo inexistente. Ante este problema, um metafísico pode propor uma melhoria no conceito de memória. Isso pode se dar de diversas maneiras. Por exemplo, o metafísico pode defender que, no final das contas, a memória é sobre o presente ao invés do passado. Ou que o passado existe, tal como defende a teoria da relatividade. Qualquer uma dessas soluções resolveria o problema da incoerência do conceito de lembrança do senso comum. Assim, o metafísico pode prescrever melhorias em conceitos. Isso é requerido no caso do diferenciador entre lembrança e imaginação, pois a metafísica do senso comum não é suficiente para estabelecê-lo. De modo que o metafísico não se limita a descrever como as pessoas pensam sobre o conceito de lembrança. Além disso, ele prescreve um uso para o termo relacionado ao conceito.

São duas as principais prescrições de definições teóricas filosóficas para o lembrar. Primeiro, de acordo com a teoria da confiabilidade, um sujeito lembra em vez de imaginar quando o mecanismo gerador de simulações de episódios busca representar o que foi passado no mundo atual e opera de maneira confiável. No entanto, essa proposta inclui um explicador inexplicado. Afinal de contas, não se explica porque o mecanismo é confiável.

Segundo, de acordo com a teoria causal, a diferenciação entre lembrar e imaginar o passado se dá porque apenas do caso do lembrar há um vínculo causal apropriado entre a experiência em $t_{1}$ e a simulação em $t_{2}$ (posterior a $t_{1}$ ) de um episódio. Esta proposta é compatível com as investigações empíricas sobre o mecanismo gerador de representações de episódios pessoais. Além disso, ela explica a confiabilidade do mecanismo, o qual é confiável porque rastreia os vínculos causais. 
Ou seja, o debate entre o teórico causal e o teórico da confiabilidade é ou sobre fatos empíricos, ou sobre o significado de termos relacionados ao conceito de memória episódica, como, por exemplo, "lembra". No entanto, o debate não é sobre fatos empíricos. Todos os participantes do debate aceitam os resultados das ciências da memória. Portanto, o debate é sobre o significado de "lembra". Assim, defendemos duas teses relacionadas ao problema do que diferencia o lembrar do imaginar o passado. Primeiro, que as duas principais teorias sobre o diferenciador da memória episódica com respeito à mera imaginação, a teoria causal e a teoria da confiabilidade, são igualmente compatíveis com os dados empíricos sobre as dimensões de semelhança entre o lembrar e o imaginar - dimensão fenomenológica, dimensão neural e dimensão funcional (SHANTON \& GOLDMAN, 2010). Isto é, ambas teorias são igualmente compatíveis com as ciências da memória que se ocupam dos mecanismos que nos habilitam a construir simulações de episódios passados ou futuros, atuais ou contrafatuais. Consequentemente, devemos resistir à implicação contida na distinção entre teorias descontinuístas e teorias continuístas de que a teoria da confiabilidade é mais "científica" do que a teoria causal (ROBINS, 2020). O debate não é sobre os fatos empíricos, mas sim sobre o significado de "lembrar", "lembrança", e outros termos relacionados.

\subsection{Uso metalinguístico}

Recapitulando, se entendemos um debate metafísico como sendo tal que cada lado simplesmente profere uma sentença verdadeira no próprio idioleto, então não há debate genuíno, pois cada lado está certo sobre o que o termo significa no idioleto. No entanto, a situação se modifica se entendemos esses debates como dizendo respeito não ao que significa um termo em um idioleto, mas sim ao que o termo deveria significar em uma linguagem partilhada (THOMASSON, 2017b, p. 2). Em cada um desses debates, e em muitos outros debates semelhantes, os participantes podem fazer uso de um termo cujo significado é disputado para mostrar como o termo deve ser empregado. Tal tipo de uso de um termo é "metalinguístico" no sentido de ser 
uma demonstração de como um termo deve ser empregado em um certo tipo de contexto (PLUNKETT \& SUNDELL, 2013).

\subsection{Justificação}

Como justificar a interpretação metalinguística de um debate que se apresenta como sendo acerca da descrição, no nível dos objetos, de alguma coisa? Os seguintes indicadores dão aval à interpretação metalinguística:

1. A condição de disputa: Há uma disputa em andamento sobre o significado de um termo.

2. A condição de desacordo: Há expressão de desacordo entre os debatedores.

3. A condição de equivocação: Há evidência de que os debatedores entendem os termos em disputa diferentemente.

4. A condição de normatividade: $\mathrm{O}$ apelo ao significado atual do termo em disputa não encerra o debate.

Se este conjunto de condições é satisfeito, então pode-se interpretar a disputa como sendo normativa, pois diz respeito não ao significado corrente de um termo, mas sim ao que o termo deveria significar (BELLERI, 2020, pp. 3-4).

O primeiro elemento, para que haja uma negociação metalinguística, é que a disputa diga respeito não aos fatos, mas sim aos padrões requeridos para se conceber os fatos. Estabelecer tais padrões é um exercício de ética conceitual, e a negociação metalinguística é uma maneira de se realizar este exercício.

O segundo elemento de uma negociação metalinguística é o objetivo partilhado entre os participantes do debate. Grosso modo, são dois os objetivos mais relevantes. Primeiro, a busca por conceitos que trinchem a natureza nas suas juntas. Neste caso, busca-se o conceito de lembrança que esteja mais próximo de como a natureza é. Contudo, no caso do conceito de lembrança, este objetivo não pode ser realizado. Segundo, a construção de um esquema conceitual para se pensar sobre o conceito de lembrança. 
As duas primeiras condições são suficientemente intuitivas, mas as duas últimas requerem esclarecimentos. Com respeito à condição de equivocação, não é nem um pouco raro que as partes do debate estejam cientes da diferença de significado. Pois considere o debate entre tridimensionalistas e quadridimensionalistas. A questão em debate é: sob quais condições um objeto concreto está plenamente dado? Por um lado, o tridimensionalista diz que basta considerar, a cada momento, o volume espacial ocupado pelo objeto. Assim sendo, cada objeto concreto está plenamente dado a cada momento. Por outro lado, o quadridimensionalista entende que um objeto concreto tem partes espaciais e partes temporais. De modo que um objeto concreto não pode estar plenamente dado a cada momento. Os dois lados entendem muito bem as definições dos oponentes. No entanto, isso não encerra o debate. Se o debate fosse encerrado pela descoberta de que cada lado fala sobre algo diferente, então não seria interessante interpretar a disputa como uma negociação metalinguística. Mas, em vez de terminar a conversa, o reconhecimento do desacordo conceitual passa para o campo normativo. A questão em disputa se modifica, ou, ao menos, é útil interpretar a questão em disputa como se modificando, e tomando a seguinte configuração:

O que se deve entender por objeto concreto: Um corpo dado em um momento do tempo ou um corpo dado em todos os momentos do tempo em que este corpo existe?

Com isso, é satisfeita a condição de normatividade.

Consideremos o debate entre McTaggart e seus críticos, os teóricosA e -B do tempo. Primeiro, há, de fato, uma disputa, pois os teóricos-A e -B do tempo não aceitam a conclusão de McTaggart que o tempo inexiste. Segundo, há suficiente informação para se concluir que há expressão de desacordo. Terceiro, há equivocação no uso de "tempo", pois cada parte determina o significado do termo segundo sua própria teoria. Por fim, o apelo ao significado de dicionário de "tempo" não encerra a disputa. Assim, trata-se de um debate ontológico que pode ser proveitosamente interpretado como uma negociação metalinguística. 
Outro exemplo é a querela dos universais. Há disputa, há desacordo, há equivocação, e há proposta do que "universal" deve significar, apesar do que de fato significa. Portanto, é outro caso no qual é fértil interpretar a disputa como sendo uma negociação metalinguística (BELLERI, 2020, p. 4).

Há, no entanto, obstáculos para a interpretação de um debate como sendo uma negociação metalinguística. Em primeiro lugar, por se considerar que não haveria margem para equivocação razoável, pode se dar que um ou ambos os lados da disputa não tenham disposição para conceder que o ponto normativo seria disputável. Em segundo lugar, o intérprete do debate pode estar motivado pelo projeto de trinchar a natureza nas suas juntas, o que o faz ou reconhecer um dos lados como vencedor, ou considerar que o debate ainda não está suficientemente maduro (BELLERI, 2020, pp. 4-5).

Uma maneira de lidar com estes problemas é distinguindo entre o fato de uma disputa ontológica ser uma negociação metalinguística e ser proveitoso interpretar uma disputa ontológica como se fosse uma negociação metalinguística. É a segunda alternativa que mais nos interessa, pois é possível encontrar variações de significado que motivariam uma negociação metalinguística mesmo em situações nas quais não há disposição para o debate sobre qual deveria ser o significado de um termo. De modo que a distinção entre ser de fato uma negociação metalinguística e poder ser interpretado como se fosse uma negociação metalinguística é importante, pois se tudo o que se pede é que seja possivel interpretar uma disputa ontológica como se fosse uma negociação metalinguística, então o ônus da prova de impossibilidade desse tipo de interpretação cabe ao crítico. Assim, é problemático descrever uma disputa ontológica como sendo um caso de negociação metalinguística, mas há espaço para se prescrever esse tipo de interpretação. Ou seja, do fato de uma disputa ontológica não ser uma negociação metalinguística não segue que não deva ser uma negociação metalinguística (BELLERI, 2020, pp. 5-6).

Mas, por que se deveria interpretar uma disputa ontológica como sendo uma negociação metalinguística? Uma razão é que, quando se percorre esse caminho, busca-se clareza sobre as regras que governam nossos conceitos para que, se requerido, se revise, se substitua, ou se elimine tais conceitos (BELLERI, 2020, p. 6). 
Outra razão é a caridade interpretativa (BELLERI, 2020, pp. 6-7). Considere o caso de Berkeley. Sua ontologia não inclui corpos entre os existentes. Justificadamente, isso abre caminho para todo tipo de reação negativa. No entanto, a situação é diferente se interpretamos Berkeley como alguém que negocia como devemos usar o conceito de corpo. Nesse caso, como é usualmente reconhecido, sua argumentação é muito bem armada e amarrada. Vista dessa maneira caridosa, como uma proposta de norma sobre a noção de corpo, o trabalho de Berkeley revela seu valor pelo cuidado e rigor na abordagem do conceito de corpo.

\section{Aplicação}

O experimento mental das máquinas Mnem-O-Matic evidencia que o tópico do debate é sobre o conceito de lembrança. Com respeito à estrutura do debate, sugerimos que o mesmo pode ser interpretado como se fosse uma negociação metalinguística (PLUNKETT \& SUNDELL, 2013; THOMASSON, 2017b; BELLERI, 2020; KITSIK, 2020). Isto é, os filósofos envolvidos no debate usam o conceito de lembrança de certa maneira para prescrever aos outros o mesmo tipo de uso (KITSIK, 2020). Quando uma máquina C-Mnem-O-Matic detecta uma cadeia causal não-desviante, o filósofo da causalidade pode usar o conceito causalista de lembrança ("Sim, é um caso de lembrança") para prescrever aos outros o mesmo tipo de uso ("Você deve aplicar o conceito de lembrança apenas às representações do passado atual que sejam causadas apropriadamente pelos episódios representados")

Agora suponha que uma máquina S-Mnem-O-Matic tenha sido usada, ao mesmo tempo, para o exame do encéfalo do mesmo participante. Caso não se detecte confiabilidade do sistema de construção de episódios, o filósofo da confiabilidade pode usar o conceito confiabilista de lembrança ("Isto não é lembrança") para prescrever o uso do conceito confiabilista de lembrança ("Você deve aplicar o conceito de lembrança apenas quando um sistema de construção de episódios que seja confiável tenta representar o passado pessoal"). Ou seja, se o filósofo da causalidade e o filósofo da confiabilidade estão em uma negociação metalinguística, então eles usam o conceito de lembrança para prescrever uma maneira de entender a natureza 
da lembrança. Dado que é frutífero entender o debate como se fosse uma negociação metalinguística, segue que o debate é prescritivo, isto é, sobre como devemos entender a natureza da lembrança.

Poderia se objetar, contra esta proposta, que a questão acerca do critério de mnemicidade diz respeito à metafísica da memória, e a metafísica (ou, ao menos, a metafísica naturalista) é uma arte dedicada a trinchar a natureza nas suas juntas (SIDER, 2011). Assim, de acordo com essa objeção, o metafísico em geral, e também o metafísico da memória, deve buscar os compromissos ontológicos e ideológicos apropriados. Isto é, o metafísico deve se comprometer ontologicamente com os tipos de objetos e eventos postulados pela melhor ciência disponível, e ideologicamente com os tipos de propriedades instanciadas por objetos e eventos que são postulados pela melhor ciência disponível. E isso é tudo o que o metafísico deve fazer. De modo que, de acordo com essa objeção, não há espaço para o tipo de negociação conceitual prescritiva que estamos propondo. Ou o metafísico tem os compromissos ontológicos e ideológicos adequados, ou não tem.

Esta objeção erra o alvo. Estamos falando de uma situação na qual cada filósofo envolvido se importa com o trinchar da natureza nas suas juntas, mas isso, por si só, não determina uma única teoria filosófica, pois o mesmo conjunto de fatos empíricos é consistente com mais de uma teoria filosófica. Isto é, se levamos a sério a tese que as ciências trincham a natureza nas suas juntas, e sabemos que as descobertas científicas não são suficientes para se distinguir o lembrar do imaginar o passado, então temos que estar abertos à possibilidade de haver uma diferença fatual que ainda não foi descoberta, mas também para a possibilidade de que haja algo relacionado às regras do uso do conceito de lembrar que explique a diferença. Essa segunda possibilidade não pode ser descartada, pois os estudos empíricos que investigam o sistema de construção de episódios supõem que os participantes das pesquisas sejam capazes de distinguir o lembrar do imaginar (ROBINS, 2020). Se tais participantes fazem isso, o fazem enquanto leigos que entendem, intuitivamente, o que é lembrar, e o que é imaginar. E claramente eles o fazem (DE BRIGARD, et al., 2013). Assim, o esclarecimento sobre esse elemento conceitual que deve distinguir o lembrar do imaginar o passado é relevante para a pesquisa empírica. E também para a metafísica. 
Poderia se objetar ainda, contra nossa proposta, que ela negligencia o fato que o filósofo da causalidade defende que há diferença de tipo entre o lembrar e o imaginar o passado, enquanto o filósofo da confiabilidade defende que há identidade de tipo entre o lembrar e o imaginar o passado (PERRIN, 2016). Dado esse fato, a questão da mnemicidade seria tal que o teórico da causalidade diria que há diferença entre lembrar e imaginar o passado, enquanto o filósofo da causalidade negaria isso. No entanto, é falso que o teórico da confiabilidade não estabelece uma diferença entre lembrar e imaginar o passado. De modo que esta objeção não nos atinge.

Além disso, é falso que os dois filósofos aceitem conjuntos diferentes de fatos, e que eles aceitem conjuntos diferentes de interpretações científicas dos fatos relevantes. De modo que é enigmática a afirmação que um filósofo aceitaria identidade de tipo entre o lembrar e o imaginar o passado, enquanto o outro filósofo negaria isso. É falso que uma das propostas seja mais "científica" do que a outra (ROBINS, 2020). Ambas propostas são plenamente compatíveis com as descobertas científicas relacionadas à habilidade de viajar no tempo subjetivo para o passado e o futuro atuais e contrafatuais (ROBINS, 2020).

Por fim, o debate sobre o critério da mnemicidade não tem elementos suficientes para responder questões sobre se lembrar e imaginar o passado são, ou não, pertencentes à mesma espécie natural (ROBINS, 2020). Uma cadeia causal pode diferenciar entre o lembrar e o imaginar o passado indiferentemente ao fato das duas variedades de estados mentais pertencerem à mesma espécie natural.

Além disso, não se conhece empiricamente tal diferenciador. Caso se conhecesse, o debate seria muito diferente. Façamos a distinção entre mnemicidade descritiva e mnemicidade normativa. A mnemicidade descritiva diz respeito ao trinchar a natureza nas suas juntas (BIRD \& TOBIN, 2017). Não existe, presentemente, critério para a mnemicidade descritiva. Se houvesse tal critério, não haveria espaço para debate do critério de mnemicidade entre filósofos empiricamente informados.

A mnemicidade normativa é sobre como devemos usar o conceito de lembrança, dado que não há solução descritiva para o problema da mnemicidade. Ora, é pedir demais dessa mnemicidade que ela seja suficiente para es- 
tabelecer, empiricamente, se duas ocorrências de estados mentais pertencem, ou não, à mesma espécie natural.

De modo que a objeção relacionada à suposta diferença de tipo não se mostra a melhor maneira de lidarmos com o problema do critério de mnemicidade.

\section{Conclusão}

Neste trabalho, buscamos apresentar o debate entre causalistas e simulacionistas em filosofia da memória como um caso de negociação metalinguística. Acreditamos que essa maneira de entender esse debate tem vantagens sobre a interpretação do mesmo como um caso de disputa sobre fatos, pois ambas as teorias são compatíveis com os mesmos fatos. Assim sendo, teríamos que dizer ou que a disputa é vazia, ou que a disputa é sobre outra coisa. Não há razão alguma para se interpretar a disputa como sendo meramente verbal, e o princípio de caridade interpretativa nos leva a buscar outra coisa que seria o tópico desse debate. A nosso ver, essa outra coisa seria o que deveríamos entender por lembrança. Assim, a disputa seria normativa em vez de descritiva.

\section{Agradecimentos}

O presente trabalho foi realizado com apoio da Coordenação de Aperfeiçoamento de Pessoal de Nível Superior - Brasil (CAPES) - Código de Financiamento 001, processo número 88887.468340/2019-00. Agradeço a Danilo Fraga Dantas, Beatriz Sorrentino Marques, Eduardo Vicentino de Medeiros, Roberto Horácio de Sá Pereira, Ernesto Perini-Santos e Matheus Diesel Werberich pela leitura de versões anteriores deste texto.

\section{Referências}

ADDIS, Donna Rose. Are episodic memories special? On the sameness of remembered and imagined event simulation. Journal of the Royal Society of New Zealand, v. 48, n. 2-3, p. 64-88, 2018. Disponível em:

$<$ https://www.tandfonline.com/doi/full/10.1080/03036758.2018.1439071>

ADDIS, Donna Rose et al. Constructive episodic simulation of the future and the past: Distinct subsystems of a core brain network mediate imagining 
and remembering. Neuropsychologia, v. 47, n. 11, p. 2222-2238, 2009. Disponível em:

$<$ https://linkinghub.elsevier.com/retrieve/pii/S0028393208004223>

ADDIS, Donna Rose; WONG, Alana T.; SCHACTER, Daniel L. Remembering the past and imagining the future: Common and distinct neural substrates during event construction and elaboration. Neuropsychologia, v. 45, n. 7, p. 1363-1377, 2007. Disponível em: $<$ https://linkinghub.elsevier.com/retrieve/pii/S0028393206004131>

ARISTÓTELES. Da memória e da revocação. In: Parva naturalia. São Paulo: Edipro, 2012.

BAKER, Chris. The dynamics of vagueness. Linguistics and Philosophy, v. 25, n. 1, p. 1-36, 2002.

BELLERI, Delia. Ontological disputes and the phenomenon of metalinguistic negotiation: Charting the territory. Philosophy Compass, 2020. Disponível em:

$<$ https://onlinelibrary.wiley.com/doi/abs/10.1111/phc3.12684>

BERNECKER, Sven. The metaphysics of memory. Dordrecht: Springer, 2008.

BERNECKER, Sven. Memory: a philosophical study. Oxford: Oxford University Press, 2010.

BERNECKER, Sven. Visual Memory and the Bounds of Authenticity. In: Mind, Language and Action: proceedings of the 36th International Wittgenstein Symposium. Berlin, München, Boston: DE GRUYTER, 2015.

BERNECKER, Sven. Memory and truth. In: BERNECKER, Sven; MICHAELIAN, Kourken (Eds.). The Routledge Handbook of Philosophy of Memory. London: Routledge, 2017a.

BERNECKER, Sven. A Causal Theory of Mnemonic Confabulation. Frontiers in Psychology, v. 8, 2017b. Disponível em:

$<$ http://journal.frontiersin.org/article/10.3389/fpsyg.2017.01207/full>

BIRD, Alexander; TOBIN, Emma. Natural Kinds. In: ZALTA, Edward N. (Ed.). The Stanford Encyclopedia of Philosophy. Spring 2018 ed. [s.1.]: Metaphysics Research Lab, Stanford University, 2018.

DE BRIGARD, Felipe. Is memory for remembering? Recollection as a form of episodic hypothetical thinking. Synthese, v. 191, n. 2, p. 155-185, 2014.

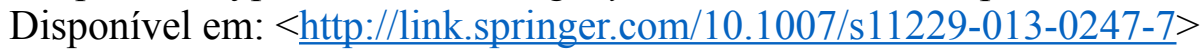

DE BRIGARD, F. et al. Remembering what could have happened: Neural correlates of episodic counterfactual thinking. Neuropsychologia, v. 51, n. 
12, p. 2401-2414, 2013. Disponível em:

$<\underline{\text { https://linkinghub.elsevier.com/retrieve/pii/S0028393213000298> }}$

CARNAP, Rudolf. Empirismo, Semântica e Ontologia. In: MARICONDA, Pablo Rúben (Ed.). Os Pensadores. 3a. ed. São Paulo: Nova Cultural, 1988. p. 113-28.

CARRUTHERS, Peters. The centered mind: what the science of working memory shows us about the nature of human thought. Oxford: Oxford University Press, 2015.

DEBUS, Dorothea. Accounting for epistemic relevance: A new problem for the causal theory of memory. American Philosophical Quarterly, v. 47, n. 1, p. 17-29, 2010.

DEBUS, Dorothea. 'Mental Time Travel': Remembering the Past, Imagining the Future, and the Particularity of Events. Review of Philosophy and Psychology, v. 5, n. 3, p. 333-350, 2014. Disponível em: $<$ http://link.springer.com/10.1007/s13164-014-0182-7>

DEUTSCHER, Max. Remembering 'Remembering'. In: HEIL, John (Ed.). Cause, Mind, and Reality. Dordrecht: Springer Netherlands, 1989. p. 53-72.

FERNÁNDEZ, Jordi. Memory: a self-referential account. Oxford: Oxford University Press, 2019.

GOODMAN, Nelson. Fact, fiction and forecast. 4a. ed. Cambridge, Massachusetts: Harvard University Press, 1979.

HACKING, Ian. Ontologia histórica. Tradução Leila Mendes; Alessandro Zir. São Leopoldo: Editora Unisinos, 2009.

HOCHSTEIN, Eric. How metaphysical commitments shape the study of psychological mechanisms. Theory \& Psychology, v. 29, n. 5, p. 579-600, 2019. Disponível em:

$<\underline{\text { http://journals.sagepub.com/doi/10.1177/0959354319860591> }}$

JAMES, William. The principles of psychology, vol. I. New York: Henry Holt and Company, 1980.

KAHNEMAN, Daniel. Rápido e devagar: duas formas de pensar. Tradução Cássio de Arantes Leite. Rio de Janeiro: Objetiva, 2012.

KITAMURA, Takashi et al. Engrams and circuits crucial for systems consolidation of a memory. Science, v. 356, n. 6333, p. 73-78, 2017. Disponível em:

$<\underline{\text { https://www.sciencemag.org/lookup/doi/10.1126/science.aam6808 }>}$ 
KITSIK, Eve. Explication as a strategy for revisionary philosophy. Synthese, v. 197, n. 3, p. 1035-1056, 2020. Disponível em:

$<\underline{\text { http://link.springer.com/10.1007/s11229-018-1774-z> }}$

KLEIN, Stanley B. What memory is. Wiley Interdisciplinary Reviews: Cognitive Science, v. 6, n. 1, p. 1-38, 2015. Disponível em:

$<\underline{\text { http://doi.wiley.com/10.1002/wcs.1333> }}$

LOCKE, Don. Memory. Garden City, NY: ANchor Books, 1971.

MAHR, Johannes B.; CSIBRA, Gergely. Why do we remember? The communicative function of episodic memory. Behavioral and Brain Sciences, v. 41, p. e1, 2018. Disponível em:

$<$ https://www.cambridge.org/core/product/identifier/S0140525X17000012/ type/journal article>

MARTIN, Charles Burton; DEUTSCHER, Max. Remembering. The Philosophical Review, v. 75, n. 2, p. 161-96, 1966.

MARTIN, C. B.; HEIL, John. The Ontological Turn. Midwest Studies In Philosophy, v. 23, n. 1, p. 34-60, 1999. Disponível em:

$<$ http://www.pdcnet.org/oom/service?url ver=Z39.88-

$2004 \&$ rft val fmt $=\& r f t$.imuse $\mathrm{id}=\mathrm{msp} 19990023 \quad 0034$ 0060\&sve id=in fo:www.pdenet.org/collection>

MCTAGGART, John; MCTAGGART, Ellis; SANTOS, César Schirmer Dos. A irrealidade do tempo. Kriterion: Revista de Filosofia, v. 55, n. 130, p. 747-764, 2014. Disponível em:

$<$ http://www.scielo.br/scielo.php?script=sci arttext\&pid=S0100-

$\underline{512 X 2014000200017 \& \operatorname{lng}=p t \& t \operatorname{lng}=p t>}$

MICHAELIAN, Kourken. Mental time travel: episodic memory and our knowledge of the personal past. Cambridge, Massachusetts: The MIT Press, 2016a.

MICHAELIAN, Kourken. Confabulating, Misremembering, Relearning: The Simulation Theory of Memory and Unsuccessful Remembering. Frontiers in Psychology, v. 7, 2016b. Disponível em:

$<\underline{\text { http://journal.frontiersin.org/article/10.3389/fpsyg.2016.01857/full }>}$

MICHAELIAN, Kourken. Confabulating as Unreliable Imagining: In Defence of the Simulationist Account of Unsuccessful Remembering. Topoi, v. 39, n. 1, p. 133-148, 2020. Disponível em:

$<$ http://link.springer.com/10.1007/s11245-018-9591-z $>$

MICHAELIAN, Kourken; DEBUS, Dorothea; PERRIN, Denis. The philosophy of memory today and tomorrow: Editors' introduction. In: MICHAELIAN, Kourken; DEBUS, Dorothea; PERRIN, Denis (Eds.). New Directions in the Philosophy of Memory. New York: Routledge, 2018. p. 19. 
MICHAELIAN, Kourken; ROBINS, Sarah K. Beyond the causal theory? Fifty years after Martin and Deutscher. In: MICHAELIAN, Kourken; DEBUS, Dorothea; PERRIN, Denis (Eds.). New directions in the philosophy of memory. London: Routledge, 2018. p. 13-32.

MICHAELIAN, Kourken; SUTTON, John. Memory. In: ZALTA, Edward N. (Ed.). The Stanford Encyclopedia of Philosophy. Summer 2017 ed. [s.l.] : Metaphysics Research Lab, Stanford University, 2017.

MOORE, A. W. The evolution of modern metaphysics: making sense of things. Cambridge: Cambridge University Press, 2012.

OKUDA, Jiro et al. Thinking of the future and past: the roles of the frontal pole and the medial temporal lobes. NeuroImage, v. 19, n. 4, p. 1369-1380, 2003. Disponível em:

$<$ https://linkinghub.elsevier.com/retrieve/pii/S1053811903001794>

PERRIN, Denis. Asymmetries in Subjective Time. In: MICHAELIAN, Kourken; KLEIN, Stnaley B.; KARL K. SZPUNAR (Eds.). Seeing the Future: Theoretical Perspectives on Future-Oriented Mental Time Travel. Oxford: Oxford University Press, 2018. p. 39-61.

PERRIN, Denis. A Case for Procedural Causality in Episodic Memory. In: MICHAELIAN, Kourken; DEBUS, Dorothea; DENIS PERRIN (Eds.). New Directions in the Philosophy of Memory. London: Routledge, 2018.

PLUNKETT, David; SUNDELL, Tim. Disagreement and the semantics of normative and evaluative terms. Philosopher's Imprint, v. 13, n. 23, 2013.

POIDEVIN, Robin Le. The images of time: an essay on temporal representation. Oxford: Oxford University Press, 2007.

QUINE, W. V. Sobre o que há. In: De um ponto de vista lógico: nove ensaios lógico-filosóficos. Tradução Antonio Ianni Segatto. São Paulo: UNESP, 2011. p. 11-36.

REESE, Elaine; CLEVELAND, Emily Sutcliffe. Mother-Child Reminiscing and Children's Understanding of Mind. Merrill-Palmer Quarterly, v. 52, n. 1, p. 17-43, 2006. Disponível em:

$<$ http://muse.jhu.edu/content/crossref/journals/merrill-palmer quarterly/ v052/52.1reese.html>

ROBINS, Sarah. Representing the past: memory traces and the causal theory of memory. Philosophical Studies, v. 173, n. 11, p. 2993-3013, 2016. Disponível em: $<\underline{\text { http://link.springer.com/10.1007/s11098-016-0647-x }>~}$

ROBINS, Sarah. Memory traces. In: BERNECKER, Sven; MICHAELIAN, Kourken (Eds.). The Routledge Handbook of Philosophy of Memory. London: Routledge, 2017. 
ROBINS, Sarah. Defending Discontinuism, Naturally. Review of Philosophy and Psychology, v. 11, n. 2, p. 469-486, 2020. Disponível em: $<$ http://link.springer.com/10.1007/s13164-020-00462-0>

ROBINS, Sarah K. Biological clocks: explaining with models of mechanisms. In: JOHN BICKLE (Ed.). Oxford Handbook of Philosophy and Neuroscience. New York: Oxford University Press, 2009. p. 41-67.

ROWLANDS, Mark. The remembered: understanding the content of episodic memory. In: MICHAELIAN, Kourken; DEBUS, Dorothea; PERRIN, Denis (Eds.). New Directions in the Philosophy of Memory. New York: Routledge, 2018. p. 279-93.

BERTRAND, Russell. Os problemas da filosofia. Tradução Jaimir Conte. Florianópolis, 2005a.

RUSSELL, Bertrand. The analysis of mind. London: Routledge, 2005b.

RYLE, Gilbert. The concept of mind: with an introduction by Daniel $C$. Dennett. Chicago: University of Chicago Press, 2002.

SANT'ANNA, André. Mental time travel and the philosophy of memory. Filosofia Unisinos, v. 19, n. 1, 2018. Disponível em:

$<$ http://revistas.unisinos.br/index.php/filosofia/article/view/15579>

SANT'ANNA, André; MICHAELIAN, Kourken. Teorias sobre o lembrar: causalismo, simulacionismo e funcionalismo. Voluntas, v. 10, n. 3, p. 8-36, 2019 .

SCHACTER, Daniel L.; ADDIS, Donna Rose; BUCKNER, Randy L. Remembering the past to imagine the future: the prospective brain. Nature Reviews Neuroscience, v. 8, n. 9, p. 657-661, 2007. Disponível em:

$<\underline{\text { http://www.nature.com/articles/nrn2213> }}$

SCHACTER, Daniel L. et al. Constructive episodic simulation, flexible recombination, and memory errors. Behavioral and Brain Sciences, v. 41, p. e32, 2018. Disponível em:

$<$ https://www.cambridge.org/core/product/identifier/S0140525X17001510/ type/journal_article>

SHANTON, Karen; GOLDMAN, Alvin. Simulation theory. Wiley Interdisciplinary Reviews: Cognitive Science, v. 1, n. 4, p. 527-538, 2010. Disponível em: $<\underline{\text { https://onlinelibrary.wiley.com/doi/abs/10.1002/wcs.33 }>}$

SIDER, Theodore R. Writing the book of the world. Oxford: Clarendon Press, 2011.

SPINELLA, Jake. Naturalized metaphysics and scientific constraint: a model-building approach. 2019. Georgia State University, 2019. 
STRAWSON, P. F. Indivíduos: um ensaio de metafísica descritiva. Tradução Plínio Junqueira Smith. São Paulo: Editora Unesp, 2019.

SUDDENDORF, Thomas; CORBALLIS, Michael C. Mental time travel and the evolution of the human mind. Genetic, Social \& General Psychology Monographs, v. 123, n. 2, p. 133-67, 1997.

SUTTON, John. Philosophy and memory traces: Descartes to connectionism. Cambridge: Cambridge University Press, 1998.

SZPUNAR, Karl K. On subjective time. Cortex, v. 47, n. 3, p. 409-411, 2011. Disponível em:

$<$ https://linkinghub.elsevier.com/retrieve/pii/S0010945210001966>

THOMASSON, Amie L. What can we do, when we do metaphysics? In: D'ORO, Giuseppina; OVERGAARD, Soren (Eds.). The Cambridge companion to philosophicla methodology. Cambridge: Cambridge University Press, 2017a. p. 101-21.

THOMASSON, Amie L. Metaphysical Disputes and Metalinguistic Negotiation. Analytic Philosophy, v. 58, n. 1, p. 1-28, 2017b. Disponível em: <http://doi.wiley.com/10.1111/phib.12087>

TULVING, Endel. Episodic and semantic memory. In: TULVING, Endel; DONALDSON, Thomas (Eds.). Organization of Memory. New York: Academic Press, 1972. p. 381-402.

TULVING, Endel. Memory and consciousness. Canadian Psychology/Psychologie canadienne, v. 26, n. 1, p. 1-12, 1985. Disponível em: $<$ http://doi.apa.org/getdoi.cfm?doi=10.1037/h0080017>

TULVING, Endel. Remembering and knowing the past. American Scientist, v. 77, p. 361-67, 1989.

TULVING, Endel. Episodic Memory: From Mind to Brain. Annual Review of Psychology, v. 53, n. 1, p. 1-25, 2002a. Disponível em:

$<\underline{\text { http://www.annualreviews.org/doi/10.1146/annurev.psych.53.100901.1351 }}$ $\underline{14>}$

TULVING, Endel. Chronesthesia: Conscious Awareness of Subjective Time. In: Principles of Frontal Lobe Function, Oxford: Oxford University Press, 2002b. p. 311-325.

TULVING, Endel; SZPUNAR, Karl K. Does the future exist? In: LEVINE, Brian; CRAIRK, Fergus I. M. (Eds.). Mind and the Frontal Lobes: Cognition, Behavior and Brain Imaging. Oxford: Oxford University Press, 2012. p. 248-63. 